\title{
Impedance spectroscopic investigation of a Rh/YSZ catalyst under polarization
}

\author{
E.A. Baranova ${ }^{\mathrm{a}}$, G. Fóti ${ }^{\mathrm{a}, *}$, H. Jotterand ${ }^{\mathrm{b}}$, and Ch. Comninellis ${ }^{\mathrm{a}}$ \\ anstitute of Chemical Sciences and Engineering, Ecole Polytechnique Fédérale de Lausanne, CH-1015 Lausanne, Switzerland \\ ${ }^{\mathrm{b}}$ Institute of Physics of the Complex Matter, Ecole Polytechnique Fédérale de Lausanne, CH-1015 Lausanne, Switzerland
}

\begin{abstract}
Electrochemical impedance spectra at $450-600{ }^{\circ} \mathrm{C}$ and $P_{\mathrm{O}_{2}}=0.5 \mathrm{kPa}$ of a rhodium catalyst interfaced with yttria-stabilizedzirconia ( $\mathrm{Rh} / \mathrm{YSZ}$ ) were compared with a model based on the mechanism of electrochemical promotion. In the proposed equivalent electric circuit, existence of an "effective" double layer at the gas-exposed catalyst surface and its potential-controlled modification via diffusion of oxygen ions between the $\mathrm{O}^{2-}$ conducting solid electrolyte support (YSZ) and the catalyst are represented by two additional elements: adsorption capacitance and Warburg impedance. Under positive polarization, the adsorption capacitance increases dramatically indicating reinforcement of the "effective" double layer at the catalyst/gas interface, in agreement with the observation known from electrochemical promotion practice that positive polarization of a rhodium electrode leads to rhodium oxide reduction, hence, to dramatic increase in catalytic reaction rate.
\end{abstract}

KEY WORDS: rhodium electrode; electrochemical promotion; rhodium oxide reduction; impedance spectroscopy.

\section{Introduction}

Rhodium is a promising candidate for use as a catalyst in several gas-phase reactions of strong environmental impact, such as the combustion of unsaturated hydrocarbons and the selective reduction of $\mathrm{NO}_{x}$ pollutants. However, despite its high activity and selectivity, a rhodium catalyst is difficult to employ because the mechanism may suddenly change depending on the reacting gas composition. The reason for this is that, unlike other noble metals of group VIII, rhodium easily forms surface oxides at high temperature in excess of oxygen, and its oxidation state strongly influences its catalytic properties. In an overall oxidizing environment, the surface of rhodium is populated primarily by $\mathrm{Rh}_{2} \mathrm{O}_{3}$ (the most common rhodium oxide), while exposure to an overall reducing gas stream predominantly yields metallic rhodium at the surface [1,2]. Rhodium catalysts were found to exhibit much higher catalytic activity in the reduced state than in the oxidized state.

It was demonstrated for several reactions, e.g. oxidation of ethylene [3-6] and propylene [7], reduction of $\mathrm{NO}$ with $\mathrm{C}_{3} \mathrm{H}_{6}[8,9]$ and $\mathrm{CO}[10]$, that the stability of the surface rhodium oxide decreases with increasing catalyst potential. According to the phenomenon of electrochemical promotion of catalysis (EPOC) [11] or nonfaradaic electrochemical modification of catalytic activity (NEMCA effect) [12] these reactions exhibit a strong electrophobic behaviour, i.e. increasing reaction rate with increase in catalyst potential $(\partial r / \partial U>0)$. It has been suggested that oxygen ion $\left(\mathrm{O}^{2-}\right)$ backspillover is responsible

\footnotetext{
* To whom correspondence should be addressed.

E-mail: gyorgy.foti@epfl.ch
}

for this effect. The presence of this species at the catalyst surface causes a weakening of the chemisorptive bond strength of electron acceptor adsorbates (oxygen), hence an easier formation of metallic rhodium.

Recently it was demonstrated that the stability of surface rhodium oxide can be affected by varying the catalyst support. The effect can be quite pronounced, as shown for the case of ethylene oxidation on rhodium catalyst dispersed on four different supports of increasing work function, $\Phi,\left(\mathrm{TiO}_{2}<\mathrm{SiO}_{2}<\mathrm{YSZ}<\mathrm{TiO}_{2}-\right.$ $4 \% \mathrm{WO}_{3}$ ) [13]. Supports with higher work function have enhanced propensity for $\mathrm{O}^{2-}$ backspillover on the catalyst surface, therefore, they promote $\mathrm{C}_{2} \mathrm{H}_{4}$ oxidation which is an electrophobic reaction.

Because of the strong dependence of catalytic activity on the oxidation state of the rhodium catalyst, the investigation of the reaction kinetics of rhodium oxide formation/decomposition under varying experimental conditions is of great importance from both theoretical and practical point of view. In the present work, an approach for better understanding the mechanism of rhodium oxide reduction has been attempted on the basis of the theory of electrochemical promotion and using impedance spectroscopy.

The approach was divided into the following stages: (i) Establishment of an equivalent circuit for the $\mathrm{O}_{2} / \mathrm{Rh} / \mathrm{YSZ}$ system based on the backspillover mechanism of electrochemical promotion. (ii) Derivation of an equivalent circuit that would correspond to the experimental data over a broad range of frequencies, and calculation of its parameters. For this purpose the impedance spectra of rhodium electrode were recorded in oxygen atmosphere under equilibrium potential and under polarization. (iii) Comparison of the experiments with the proposed model. 


\section{Experimental}

The experimental set-up used in this study was described in detail elsewhere $[14,15]$. The cell configuration used for impedance measurements is shown in figure 1A, where two rhodium electrodes of $40 \mathrm{~nm}$ thickness and of $0.18 \mathrm{~cm}^{2}$ geometric surface area were deposited by sputtering [5] on one side of an yttriastabilized zirconia (YSZ 8 mol\%, Technox 802 from Dynamic Ceramic) support. A gold counterelectrode was deposited on the other side of the YSZ pellet [5]. A schematic representation of the polarization mode is shown in figure 1B. Direct polarization of the working electrode was accomplished by using the gold counterelectrode, while alternative current was applied between the two $\mathrm{Rh}$ electrodes, one of them serving as working electrode and the other as auxiliary electrode. This unusual arrangement was chosen due to the difficulty in realizing a solid electrolyte cell with an auxiliary electrode of much higher surface area than that of the working electrode, which is a common requirement for impedance measurements.

Impedance measurements were performed with a potentiostat (Autolab, PGSTAT30, Eco Chemie) using Frequency Response Analyser software (version 4.9). Measurements were made at the equilibrium potential and under polarization $(0-0.2 \mathrm{~V})$, always sweeping from high to low frequencies over the range from $50 \mathrm{kHz}$ to $0.1 \mathrm{~Hz}$. Using two $\mathrm{Rh}$ electrodes (working and auxiliary) with equal surface area allowed obtaining the impedance of the working electrode both under open circuit and under polarisation. Under open circuit the total impedance can be divided into two components:

$$
Z_{\mathrm{t}}=2 Z_{\mathrm{Rh} / \text { o.c. }}+R_{\mathrm{el}}
$$

to give

$$
Z_{\mathrm{Rh} / \text { o.c. }}=\left(Z_{\mathrm{t}}-R_{\mathrm{el}}\right) / 2
$$

where $Z_{\mathrm{t}}$ is the total impedance of the electrochemical cell, $Z_{\mathrm{Rh} / \text { o.c. }}$ is the impedance of one $\mathrm{Rh}$ electrode under open circuit, and $R_{\mathrm{el}}$ is the electrolyte resistance. Under polarization the measured impedance consists of the impedance of the working electrode under polarisation with contributions from the non-polarized auxiliary electrode $\left(Z_{\mathrm{Rh} / \text {..c. }}\right)$ and from the electrolyte:

$$
Z_{\mathrm{t} / \mathrm{pol}}=Z_{\mathrm{Rh} / \mathrm{pol}}+Z_{\mathrm{Rh} / \mathrm{o} . \mathrm{c}}+R_{\mathrm{el}}
$$

and

$$
Z_{\mathrm{Rh} / \mathrm{pol}}=Z_{\mathrm{t} / \mathrm{pol}}-\left(Z_{\mathrm{t}}+R_{\mathrm{el}}\right) / 2
$$

where $Z_{\mathrm{Rh} / \mathrm{pol}}$ is the impedance of the $\mathrm{Rh}$ electrode under polarization, and $Z_{\mathrm{t} / \mathrm{pol}}$ is the total impedance of the electrochemical cell under polarisation. In this way one can determine the impedance of the working electrode alone, and investigate the electrode process including the reactions occurring only at the rhodium electrode.

The temperature dependence was investigated over the range between 450 and $600{ }^{\circ} \mathrm{C}$. The impedance
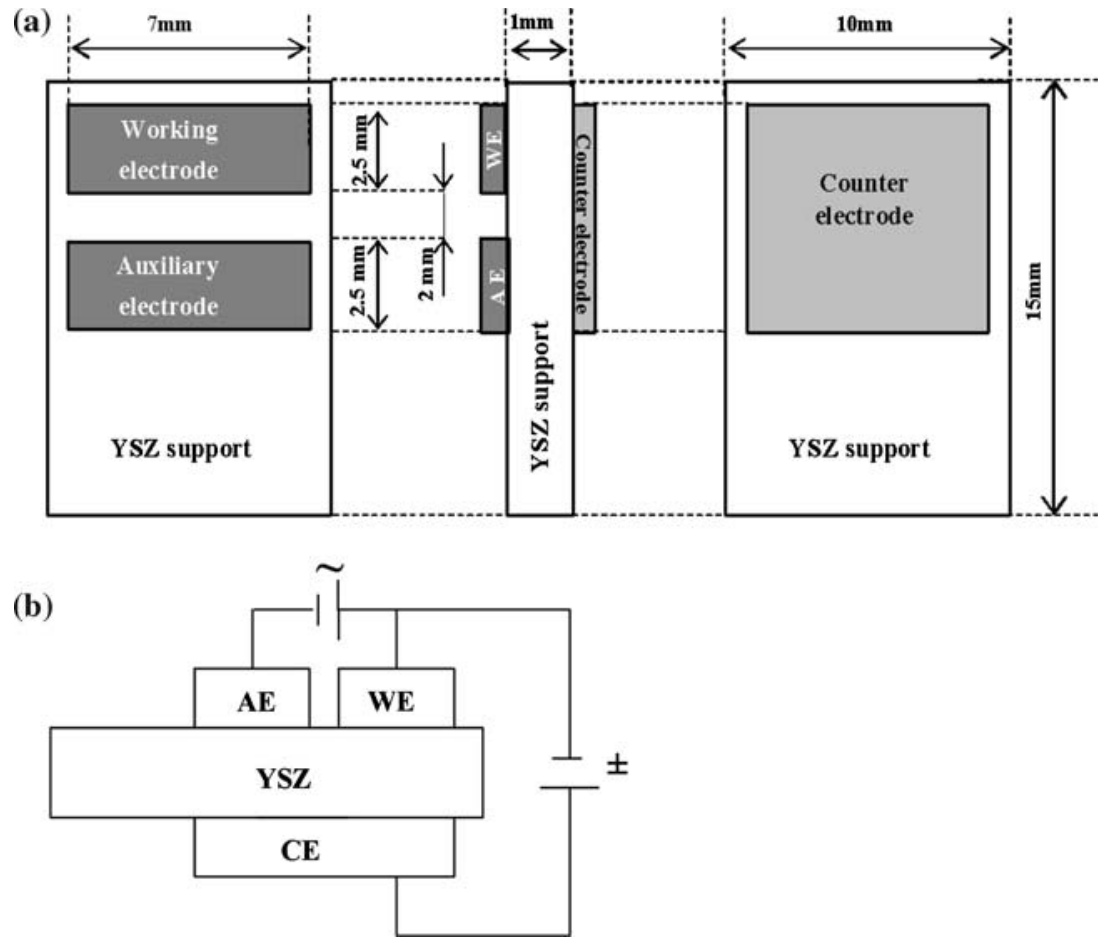

Figure 1. Schematic representation of a single-pellet cell for impedance spectroscopy studies. A, Electrochemical cell; B, Polarization mode. WE, working electrode; AE, auxiliary electrode; $\mathrm{CE}$, counterelectrode. 
measurements were always made at constant oxygen partial pressure $\left(P_{\mathrm{O}_{2}}=0.5 \mathrm{kPa}\right)$ and proceeding in the direction from lower to higher temperature.

\section{Results and discussion}

Under open-circuit conditions in an oxidizing atmosphere at high temperature the rhodium surface is mainly oxidized and the oxidation process can be described as follows:

$$
2 \mathrm{Rh}+3 / 2 \mathrm{O}_{2} \rightarrow \mathrm{Rh}_{2} \mathrm{O}_{3} .
$$

In general, the surface reaction of oxide formation is not a faradaic process but, as it has been shown [16,17], electron transfer steps are involved. Thus in an oxygen atmosphere the redox equation (2) can be divided on two half-reactions of oxygen reduction and oxygen evolution. The cathodic process of $\mathrm{O}_{2}$ reduction can be written as:

$$
1 / 2 \mathrm{O}_{2}+2 \mathrm{e}^{-}(\mathrm{Rh}) \rightarrow \mathrm{O}^{2-} .
$$

The anodic process of oxygen evolution is:

$$
\mathrm{O}^{2-}-2 \mathrm{e}^{-} \rightarrow 1 / 2 \mathrm{O}_{2} .
$$

The surface rhodium oxide is a poor catalyst and shows high stability against reduction. Its decomposition requires either the change of the gaseous composition to reducing atmosphere or application of positive polarization to the rhodium electrode according to electrochemical promotion of catalysis [12]. The electrode reactions (equations 3,4 ) alone are not able to explain why a positive potential application decreases the stability of $\mathrm{Rh}_{2} \mathrm{O}_{3}$.

It was well established by different techniques [12], that under the given experimental conditions the catalyst surface is populated by two types of oxygen: catalytically active oxygen species adsorbed from the gas phase and linked with rhodium as $\mathrm{Rh}_{2} \mathrm{O}_{3}$ on one hand, and backspillover oxygen from the YSZ solid electrolyte $\left(\mathrm{O}^{2-}\right)$ on the other hand. The amount of $\mathrm{O}^{2-}$ on the catalyst surface will depend on the applied potential but there is a finite population already under open circuit conditions. The oxygen ions at the surface are accompanied by their compensating image charge in the electrode, with which they form surface dipoles. When this dipoles spread out, an overall neutral effective double layer is built up at the gas-exposed electrode surface. The concomitant change in the catalyst work function acts so as to modify the binding strength of chemisorptive reactants. Positive polarisation causes weakening of the chemisorptive bond strength of electron acceptor adsorbates (e.g. oxygen) making easier the reduction of surface oxide to metallic rhodium [3-7].

Electrode reactions (equations 3,4) as well as the above described mechanism of backspillover have served as a base for the design of a theoretical equivalent circuit. An electric equivalent circuit of the rhodium electrode-catalyst in contact with solid electrolyte in oxygen atmosphere is presented in figure 2 [18]. It consists of an electrolyte resistance $\left(R_{\mathrm{el}}\right)$, resistance of yttriastabilized zirconia; a double layer capacitance $\left(C_{\mathrm{dl}}\right)$ which represents the double layer formed at the $\mathrm{Rh} / \mathrm{YSZ}$ interface ("classical" double layer); a resistance of electrode process $\left(R_{\mathrm{F}}\right)$ which corresponds to reactions (3) and (4); an adsorption capacitance $\left(C_{\mathrm{a}}\right)$ describing oxygen ion adsorption on the gas-exposed rhodium surface and formation of an "effective" double layer; a Warburg impedance $\left(Z_{\mathrm{w}}\right)$ which reflects diffusion of $\mathrm{O}^{2-}$ from YSZ to the gas-exposed rhodium surface. The admittance of the rhodium electrode $(Y)$ without taking into account the electrolyte resistance can be represented as follows [18]:

$Y=1 / Z=j \omega C_{\mathrm{dl}}+R_{\mathrm{F}}^{-1}+\left(\left(j \omega C_{\mathrm{a}}\right)^{-1}+(1-j) \omega^{-1 / 2} A\right)^{-1}$

where $Z$ is the impedance of rhodium electrode; $j$ is the imaginary number; $\omega$ is the rotation frequency; $A$ is the constant of Warburg impedance.

For the $\mathrm{O}_{2} / \mathrm{Rh} / \mathrm{YSZ}$ system the equivalent circuit (figure 2) first proposed by Povorov et al. for describing the corrosion of lithium electrode in a lithium battery [19-21] is adopted. Recently, the same equivalent circuit was derived theoretically by Kuznetsov and Netesa for the corrosion of lithium electrode in the system lithium/ passivation-film/electrolyte [22].

In order to confirm the proposed equivalent circuit (figure 2) by comparison with that derived from experimental results, the set of experimental data was fitted using a frequency response analysis (FRA) program.

\subsection{Impedance measurements at equilibrium potential}

Typical experimental impedance spectra obtained for rhodium electrodes interfaced with YSZ at open circuit, constant oxygen partial pressure $\left(P_{\mathrm{O}_{2}}=0.5 \mathrm{kPa}\right)$ and different temperature $\left(T=450-600{ }^{\circ} \mathrm{C}\right)$ are shown in figure 3. These spectra consist of two semicircles: one at

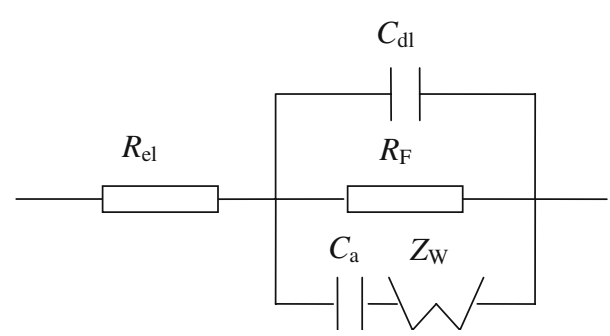

Figure 2. Equivalent electric circuit for the admittance of the $\mathrm{O}_{2} / \mathrm{Rh} /$ YSZ system. $R_{\mathrm{el}}$ is the electrolyte resistance; $C_{\mathrm{dl}}$ is the double layer capacitance (electrolyte/catalyst interface); $R_{\mathrm{F}}$ is the resistance of electrode process; $C_{\mathrm{a}}$ is the adsorption capacitance (catalyst/gas interface); $Z_{\mathrm{W}}$ is the Warburg impedance. 
high frequencies $(50 \mathrm{kHz}-2 \mathrm{kHz})$, which is a semicircle centred on the real axis, and the other at low frequencies $(1 \mathrm{kHz}-0.1 \mathrm{kHz})$ having its centre shifted below the real axis. The high-frequency semicircle is attributed to the bulk properties of the solid electrolyte [23,24]. It changes when varying the working temperature, since the conductivity of the solid electrolyte changes with temperature
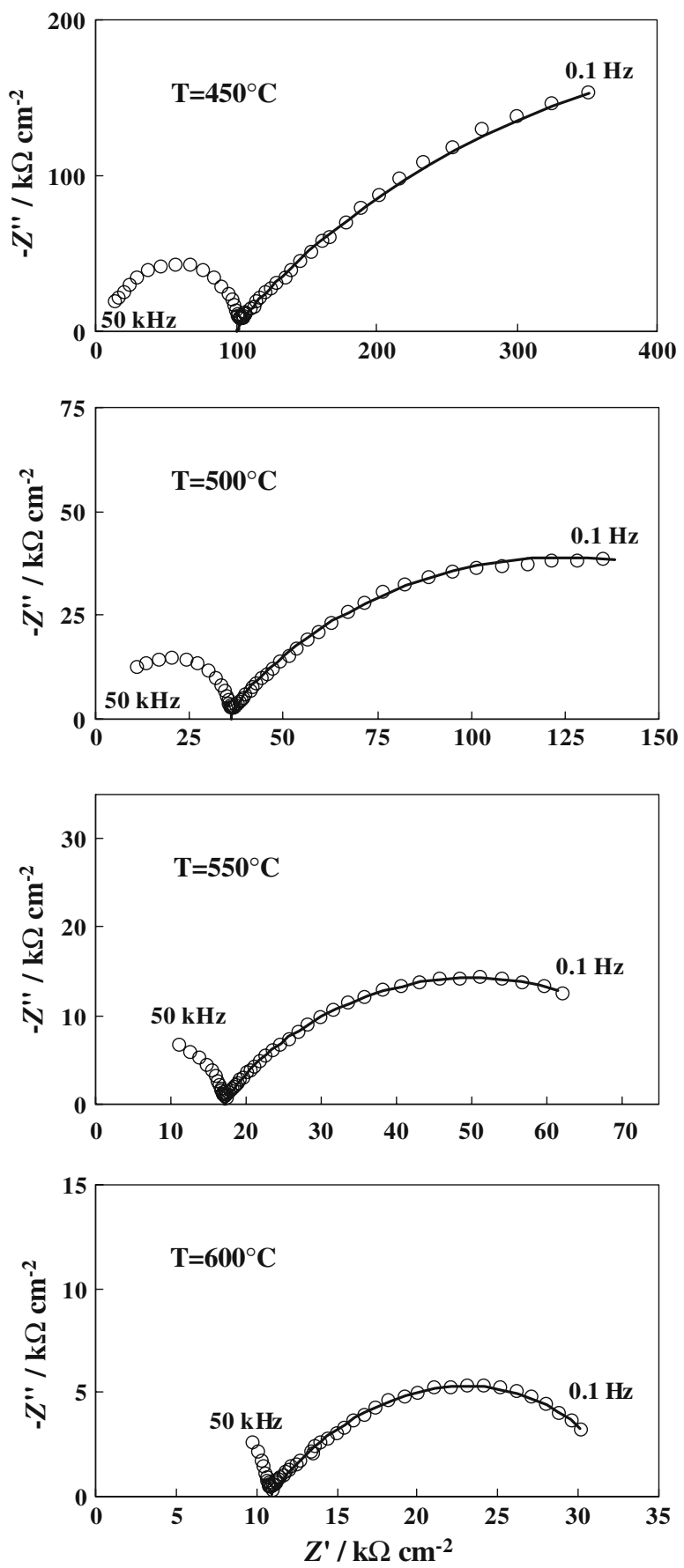

Figure 3. Experimental impedance spectra (symbols) and theoretical spectra (solid lines) obtained with the equivalent circuit given in figure 2 for a $\mathrm{Rh} / \mathrm{YSZ}$ electrode at equilibrium potential. $P_{\mathrm{O}_{2}}=0.5 \mathrm{kPa}$, temperature as indicated. but remains constant when applying a polarizing potential. The first semicircular arc corresponds to parallel $R-C$ circuit elements, $R$ being related to the electrolyte resistance and $C$ representing the geometric capacitance of the samples [24]. The second semicircle is related to the electrode process and the analysis was mainly focused on it.

Figure 3 shows a good agreement between the experimental impedance spectra (symbols) and the impedance spectra simulated with the theoretical equivalent circuit (solid lines) for a rhodium electrode interfaced with YSZ solid electrolyte. One can see how the spectra change with temperature within a constant domain of frequencies $(50 \mathrm{kHz}-0.1 \mathrm{~Hz})$ reflecting an increase in rate of the electrode process with temperature. It is interesting to note that the semicircle of the electrode process can only be observed at temperatures above $400{ }^{\circ} \mathrm{C}$, while the first semicircle almost disappears at $600{ }^{\circ} \mathrm{C}$. The results of simulation obtained when employing the equivalent circuit (figure 2) are in very good agreement with the experimental data obtained in the $\mathrm{Rh} / \mathrm{YSZ}$ system, and the reproducibility is satisfactory. The parameters extracted for the electric equivalent circuit for admittance of the rhodium electrode in oxygen at different temperatures are listed in table 1.

The observations may be summarized as follows: Total electrolyte resistance, $R_{\mathrm{el}}$, determined as the intersection of the high frequency part of the second semicircle with the real axis. It decreases with increasing temperature. The apparent activation energy of the electrolyte conductivity is $78 \mathrm{~kJ} \mathrm{~mol}^{-1}$. Double layer capacitance, $C_{\mathrm{dl}}$, is related to the electric double layer at the rhodium/YSZ interface. No distinct temperature dependence could be observed. It appears that $C_{\mathrm{dl}}$ remains rather constant while the temperature increases. Charge transfer resistance, $R_{\mathrm{F}}$, decreases with increasing temperature, which implies increasing reaction rates of the processes (equations 3,4 ) by activation energy of $130 \mathrm{~kJ} \mathrm{~mol}^{-1}$. Adsorption capacitance, $C_{\mathrm{a}}$, at the equilibrium potential, it corresponds to adsorption of oxygen ions at the rhodium-metal/gas interface, where they are equilibrated electrostatically by their mirror charge in the metal. These oxygen ions at the surface are in equilibrium with oxygen ions in the solid electrolyte [12]. At the rhodium electrode, the $C_{\mathrm{a}}$ values derived are much higher than the values of double layer capacitance. It also appears that the adsorption capacitance is independent of temperature over the range between 450 and $600{ }^{\circ} \mathrm{C}$. Mass transfer resistance, $Z_{\mathrm{W}}$, (Warburg impedance) in the model described above, this quantity is related to the process that is limited by diffusion of oxygen ions from YSZ toward the rhodium/gas interface. As expected, this parameter decreases with increasing temperature. The activation energy of the diffusion process behind the Warburg impedance is $52 \mathrm{~kJ} \mathrm{~mol}^{-1}$. 
Table 1

Parameters of the electric equivalent circuit for admittance of the $\mathrm{O}_{2} / \mathrm{Rh} / \mathrm{YSZ}$ system at equilibrium potential in $0.5 \mathrm{kPa}$ of oxygen

\begin{tabular}{lccccc}
\hline$T\left({ }^{\circ} \mathrm{C}\right)$ & $R_{\mathrm{el}}\left(\mathrm{k} \Omega \mathrm{cm}^{-2 *}\right)$ & $C_{\mathrm{dl}}\left(\mu \mathrm{F} \mathrm{cm}{ }^{-2 *}\right)$ & $R_{\mathrm{F}}\left(\mathrm{k} \Omega \mathrm{cm}^{-2 *}\right)$ & $C_{\mathrm{a}}\left(\mu \mathrm{F} \mathrm{cm} \mathrm{cm}^{-2 *}\right)$ & 130 \\
\hline 450 & 106 & 1.6 & 814 & 133 & 2.9 \\
500 & 37.4 & 1.0 & 146 & 143 & 1.6 \\
550 & 18.1 & 1.2 & 21.5 & 131 & 0.8 \\
600 & 11.4 & 1.4 & $\left.\mathrm{~km} \mathrm{~cm}^{-2 *}\right)$ & 0.7 \\
\hline
\end{tabular}

$R_{\mathrm{el}}$ is the electrolyte resistance; $C_{\mathrm{dl}}$ is the double layer capacitance; $R_{\mathrm{F}}$ is the resistance of electrode process; $C_{\mathrm{a}}$ is the adsorption capacitance; $Z_{\mathrm{W}}$ is the Warburg impedance.

${ }^{*}$ Geometric surface area of the electrode.

\subsection{Impedance measurements under polarization}

Useful information about the kinetics of the electrode process and about the characteristics of the system itself can be gained from impedance measurements under polarization. It is clear that at overpotentials of $|\eta|>10 \mathrm{mV}$, the rate of either the anodic or the cathodic process will increase dramatically, depending on the sign of applied potential. Consequently, the theoretical equivalent circuit (figure 2) then corresponds either to oxygen evolution mediated by rhodium oxide or to oxygen reduction.

Figure 4 shows experimental impedance spectra recorded under anodic and under cathodic polarization at $600{ }^{\circ} \mathrm{C}$ of a rhodium electrode interfaced with YSZ. The electrolyte resistance $\left(11.4 \mathrm{k} \Omega \mathrm{cm}^{-2}\right.$ at $\left.600{ }^{\circ} \mathrm{C}\right)$ has already been subtracted from the spectra. The experimental spectra (symbols) coincide well with those (solid lines) derived from the theoretical model and the theoretical equivalent circuit given in figure 2. Note that impedance measurements under polarization were carried out at different temperatures between 450 and $600{ }^{\circ} \mathrm{C}$. For each temperature, good agreement between the experimental and theoretical results was found, which implies that both the anodic and the cathodic process on rhodium/YSZ is readily described by the equivalent circuit proposed.

The parameters of impedance of the Rh/YSZ electrode calculated by using the theoretical equivalent circuit (figure 2) are summarized in figure 5. They are shown as functions of applied potential. The parameters of the experimental electric equivalent circuits for admittance of the rhodium electrode at different potentials are in good agreement with the mechanism proposed for the case of anodic and cathodic polarization. It is interesting to comment on the behaviour of double layer and adsorption capacitances of the rhodium electrode (figure 5). The double layer capacitance slightly decreases with increasing negative potential, while the adsorption capacitance significantly increases with increasing positive polarization and remains fairly constant under negative polarization.

In the work of Vayenas and co-workers [25] exploring the origin of electrochemical promotion, the technique of electrochemical impedance spectroscopy provided evidence for the formation of an "effective double layer" across the entire gas-exposed electrode surface. The capacitance of this metal/gas double layer was found to be much higher (order of magnitude: $200 \mu \mathrm{F} \mathrm{cm}^{-2}$ [25]; values between 100 and $300 \mu \mathrm{F} \mathrm{cm} \mathrm{cm}^{-2}$ in the present work) than that of the metal/solid-electrolyte double layer $\left(0.1-10 \mu \mathrm{F} \mathrm{cm}^{-2}\right.$ [25]; $C_{\mathrm{dl}}$ values between 0.4 and $2 \mu \mathrm{F} \mathrm{cm}^{-2}$ in the present work).

Increasing potential leads to increasing mass transfer resistance. This is understandable, since positive polarization enhances the electrode charge density and
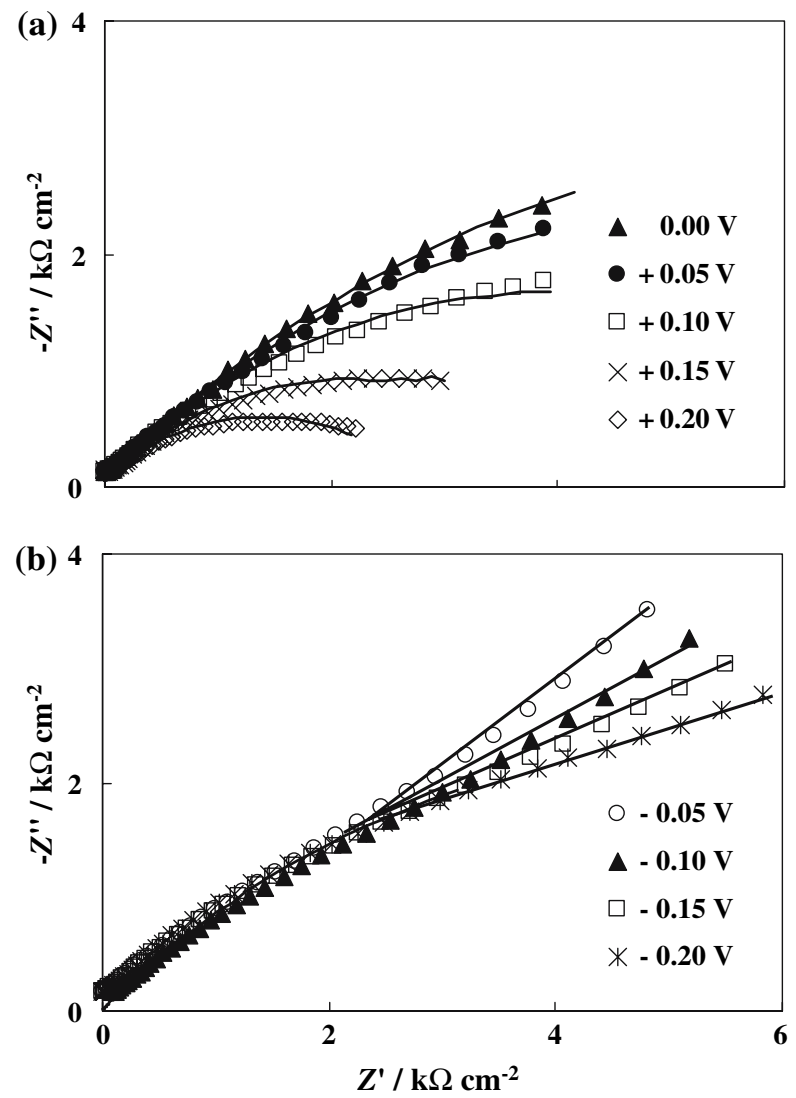

Figure 4. Impedance spectra obtained for a $\mathrm{Rh} / \mathrm{YSZ}$ electrode at different positive (A) and negative (B) catalyst potentials. $T=600{ }^{\circ} \mathrm{C}$, $P_{\mathrm{O}_{2}}=0.5 \mathrm{kPa}$. Symbols correspond to experiment, lines correspond to prediction. 

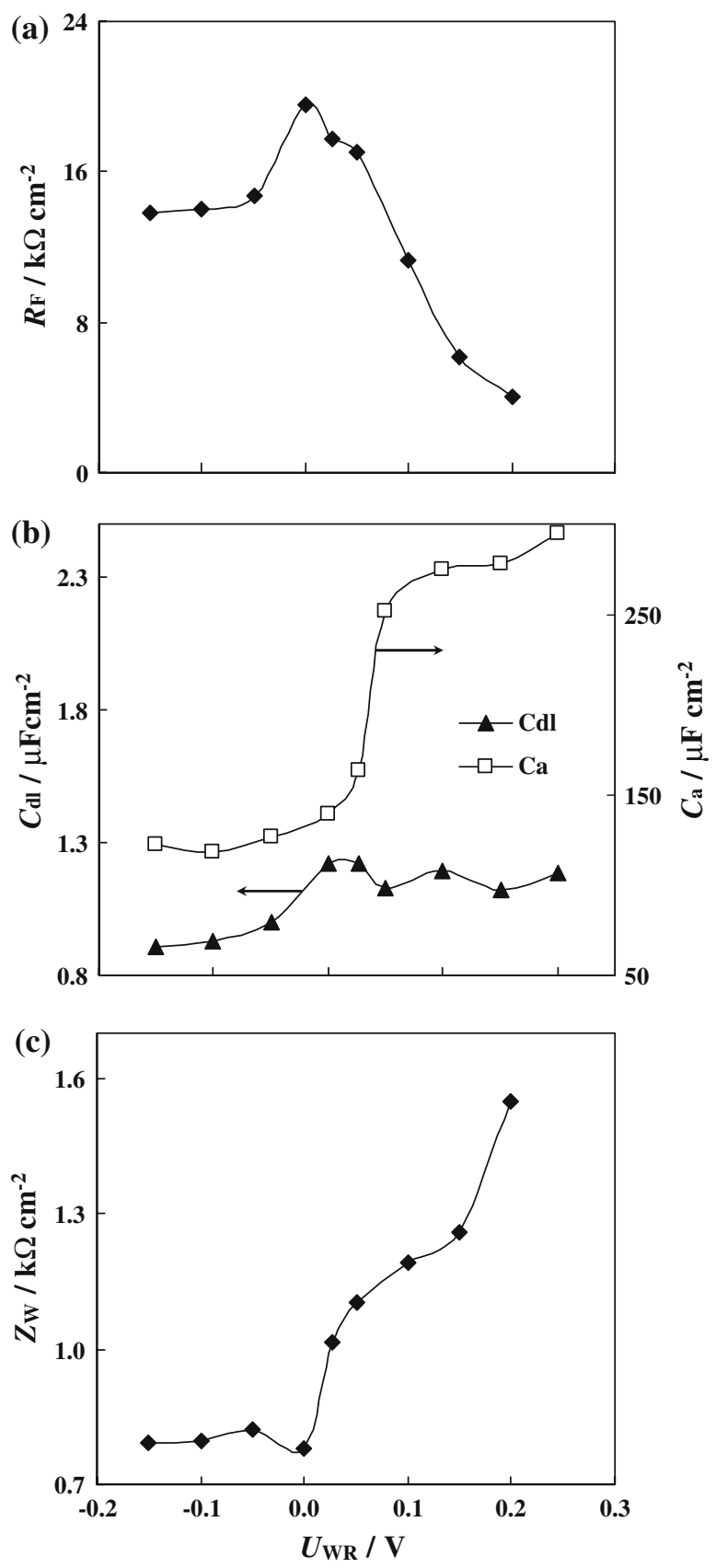

Figure 5. Parameters of the electric equivalent circuit for admittance of the $\mathrm{Rh} / \mathrm{YSZ}$ electrode under polarization as a function of applied potential, $U_{\mathrm{WR}} . P_{\mathrm{O}_{2}}=0.5 \mathrm{kPa}, T=600{ }^{\circ} \mathrm{C}$. $R_{\mathrm{F}}$ is the resistance of electrode process; $C_{\mathrm{dl}}$ is the double layer capacitance (electrolyte/ catalyst interface); $C_{\mathrm{a}}$ is the adsorption capacitance (catalyst/gas interface); $Z_{\mathrm{W}}$ is the Warburg impedance.

necessitates more negative charges neutralizing this charge. Negative polarization remains without influence on the Warburg impedance, which confirms no limitation of the process by mass transfer.

\section{Conclusion}

In the present paper a rhodium electrode interfaced with YSZ solid electrolyte has been investigated using impedance spectroscopy. At the equilibrium potential in the presence of oxygen, rhodium is being oxidized and this process consists of two half reactions: oxygen reduction and oxygen evolution. In addition, the reaction mechanism includes diffusion of oxygen ions and formation of an "effective" double layer at the gasexposed rhodium surface. On the basis of this mechanism an equivalent electric circuit was proposed. Experimental results obtained are in good accord with theoretical impedance representations of the reaction processes at rhodium electrode. The decomposition of rhodium oxide under anodic polarization, well known from electrochemical promotion practice, manifested itself by high values of adsorption capacitance $\left(>100 \mu \mathrm{F} \mathrm{cm}^{-2}\right.$ ) at the catalyst/gas interface and by its strong positive dependence of the applied potential.

\section{Acknowledgment}

Financial support from the Fonds National Suisse de la Recherche Scientifique is gratefully acknowledged.

\section{References}

[1] S.H. Oh and J.E. Carpenter, J. Catal. 80 (1983) 472.

[2] G.L. Kellog, Surface Sci. 171 (1986) 359.

[3] C. Pliangos, I.V. Yentekakis, X.E. Verykios and C.G. Vayenas, J. Catal. 154 (1995) 124.

[4] C. Pliangos, I.V. Yentekakis, S. Ladas and C.G. Vayenas, J. Catal. 159 (1996) 189.

[5] E.A. Baranova, A. Thursfield, S. Brosda, G. Fóti, Ch. Comninellis and C.G. Vayenas, J. Electrochem. Soc. 152 (2005) E40.

[6] E.A. Baranova, A. Thursfield, S. Brosda, G. Fóti, Ch. Comninellis and C.G. Vayenas, Catal. Lett. 105 (2005) 15.

[7] G. Fóti, I. Bolzonella, D. Bachelin and Ch. Comninellis, J. Appl. Electrochem. 34 (2004) 9.

[8] G. Fóti, O. Lavanchy and Ch. Comninellis, J. Appl. Electrochem. $30(2000) 1223$.

[9] C. Pliangos, C. Raptis, T. Badas and C.G. Vayenas, Solid State Ionics 136-137 (2000) 767.

[10] C. Pliangos, C. Raptis, T. Badas and C.G. Vayenas, Ionics 6 (2000) 119.

[11] C.G. Vayenas, S. Bebelis and S.G. Neophytides, J. Phys. Chem. 92 (1988) 5083.

[12] C.G. Vayenas, S. Bebelis, C. Pliangos, S. Brosda and D. Tsiplakides, Electrochemical Activation of Catalysis. Promotion, Electrochemical Promotion, and Metal-support Interaction, (Kluwer Academic/Plenum Publishers, New York, 2001).

[13] J. Nicole, D. Tsiplakides, C. Pliangos, X.E. Verykios, Ch. Comninellis and C.G. Vayenas, J. Catal. 204 (2001) 23.

[14] G. Fóti, S. Wodiunig and Ch. Comninellis, in: Current Topics in Electrochemistry, Vol. 7 (Research Trends, Trivandrum, 2000) p. 1.

[15] E.A. Baranova, G. Fóti and Ch. Comninellis, Electrochem. Comm. 6 (2004) 170

[16] F.S. Pettit, F.S. Yinger and J.B. Wagner, Acta Metal. 8 (1960) 617.

[17] F.S. Pettit and J.B. Wagner, Acta Metal. 12 (1964) 35.

[18] E.A. Baranova Chemical and electrochemical promotion of supported rhodium catalyst, Thesis 3245, EPFL, Lausanne (2005).

[19] Y.M. Povorov and I.V. Vorob'eva, Elektrokhimiya 18 (1982) 1693. 
[20] Y.M. Povorov, L.A. Beketaeva and I.V. Vorob'eva, Elektrokhimiya 19 (1983) 586.

[21] L.S. Kanevskiy, M.B. Avdolyan and T.L. Kulova, Elektrokhimiya 31 (1995) 383.

[22] A.A. Kuznetsov and V.V. Netesa, Ukr. Chim. J. 65 (1999) 126.

[23] V.N. Chebotin and M.V. Perfilev, Electrochemistry of Solid Electrolytes (Khimiia Publ. House, Moscou, 1978).
[24] C. Deportes, M. Duclot, P. Fabry, J. Fouletier, A. Hammou, M. Kleitz, E. Siebert and J.-L. Souquet, Electrochimie des solides (Grenoble University Press, Grenoble, 1994).

[25] A.D. Frantzis, S. Bebelis and C.G. Vayenas, Solid State Ionics 136-137 (2000) 863. 